BONPLANDIA 20(2). 2011

ISSN: 0524-0476

\title{
INCORPORACIÓN Y APREHENSIÓN DE SABERES SOBRE PLANTAS ÚTILES A PARTIR DEL JUEGO: PRÁCTICAS DE EXTENSIÓN EN BOTÁNICA APLICADA
}

\author{
MARÍA LELIA POCHETTINO, AYLEN CAPPARELLI, PATRICIA ARENAS, VERÓNICA LEMA, PATRICIA RIAT, \\ AMPARO BECERRA, MATÍAS BENAVIDES, SEBASTIÁN CARREÑO, CANELA CASTRO, IVANA FARELLA, \\ VANINA GUEVARA, MARCELO KOSTLIN, DÉBORA PEDEMONTE ROMÁN, MAGALI PÉREZ FLORES, MARÍA \\ LAURA PIPO, ROCÍO RIVIRA \& SOFÍA SIVERO'
}

Summary: Pochettino, M. L., A. Capparelli, P. Arenas, V. Lema, P. Riat, A. Becerra, M. Benavides, S. Carreño, C. Castro, I. Farella, V. Guevara, M. Kostlin, D. Pedemonte Román, M. Pérez Flores, M. L. Pipo, R. Rivira \& S. Sivero. 2011. The aprehension of knowledge about useful plants through the games: practices of universitary extension in Economic Botany. Bonplandia 20(2): 149-163.

Taking as a starting point the conception that universitary extension, in conjunction with research and teaching, is one of the basis of modern university, we develop practices that relate our researches on applied ethnobotany with teaching-learning process in Economic Botany, and the application of this knowledge to the resolution of everyday problems. We present the results of an experience, devoted to children and teenagers that are hospitalized, that links, through different games, plants of customary use with current wisdoms in different contexts.

Key words: Applied ethnobotany, educative games, universitary extension.

Resumen: Pochettino, M. L., A. Capparelli, P. Arenas, V. Lema, P. Riat, A. Becerra, M. Benavides, S. Carreño, C. Castro, I. Farella, V. Guevara, M. Kostlin, D. Pedemonte Román, M. Pérez Flores, M. L. Pipo, R. Rivira \& S. Sivero. 2011. Incorporación y aprehensión de saberes sobre plantas útiles a partir del juego: prácticas de extensión en Botánica Aplicada. Bonplandia 20(2): 149-163.

A partir de la concepción de que la extensión universitaria constituye un pilar conceptual e ideológico de la Universidad Reformista junto a la enseñanza y la investigación, se desarrollan prácticas que vinculan las investigaciones sobre etnobotánica aplicada con la tarea docente en Botánica Aplicada y su transferencia a la resolución de problemas cotidianos. Se presentan los resultados de una experiencia destinada a niños y jóvenes que están sometidos a internación hospitalaria que, a través del juego, vincula vegetales de uso habitual con los saberes vigentes en distintos ámbitos.

Palabras clave: Etnobotánica aplicada, juegos educativos, extensión universitaria.

\section{A modo de dedicatoria y también agradecimiento}

Siempre es arriesgado suponer que opinarían quiénes ya no están. Sin embargo, deseamos creer que al Ing. Martínez Crovetto, a quien va dirigida nuestra dedicatoria, le hubiera interesado este trabajo. Sus publicaciones

${ }^{1}$ Cátedra de Botánica Aplicada, Facultad de Ciencias Naturales y Museo, Universidad Nacional de La Plata. Calle 64 n 3, 1900 La Plata, Argentina. pochett@fcnym.unlp.edu.ar 
sobre juegos de distintos pueblos originarios (Martínez Crovetto, 1968a,b,c,d,e, 1969, 1970) constituyeron el disparador de esta propuesta y probablemente de no haber contado con ellas, esta actividad no se hubiera realizado. Agradecemos también a todos los alumnos de Botánica Aplicada, que a lo largo del tiempo han planteado diversos desafíos y nos han obligado a enfrentarlos, así como a los distintos sectores de la comunidad que nos reciben y comparten estas experiencias.

\section{Introducción}

\section{Investigación, docencia y extensión}

Desde hace 20 años se desarrollan investigaciones sobre etnobotánica aplicada en el Laboratorio de Etnobotánica y Botánica Aplicada, en conjunción con la actividad docente a través de la asignatura Botánica Aplicada. Como parte del dictado de esta materia, desde 2005, se han incorporado las Prácticas de Extensión en consonancia con la iniciativa implementada por la Secretaría de Extensión de nuestra facultad.

La Extensión Universitaria, constituye un pilar conceptual e ideológico de la Universidad Reformista, junto a la enseñanza y la investigación. En este marco, las Prácticas de Extensión constituyen un espacio de enseñanza y aprendizaje extracurricular que tiene como objetivos generar un espacio de aplicación de los saberes generados en el ámbito universitario, espacio en el cual los actores universitarios (docentes y alumnos) interactúen con miembros de la sociedad en el planteamiento de soluciones a problemas concretos, aportando cada uno sus saberes, prácticas e historias a la idea/producto en desarrollo. Asimismo, propone fomentar la valoración de las actividades de extensión en las Cátedras y promover el trabajo grupal e interdisciplinario en el abordaje de dichos problemas.

En el caso particular de las prácticas de extensión en Botánica Aplicada, las actividades desarrolladas tienen como objetivo minimizar la pérdida del conocimiento botánico local, promover el uso de recursos vegetales y productos derivados en condiciones óptimas de calidad e involucrar a las nuevas generaciones en estas iniciativas.

Generalmente los estudios etnobotánicos se han centrado en el conocimiento que poseen diversos grupos indígenas y/o campesinos ya que en ellos las relaciones entre las plantas y el hombre son más claras que en nuestra propia sociedad, pues el nexo entre producción y consumo es más directo. No obstante en áreas urbanas, los elementos vegetales, generalmente industrializados, revisten la misma importancia para la vida del Hombre que en áreas rurales, pero la pérdida de saberes descripta precedentemente se revela más rápida y profundamente que en otros contextos (Pochettino \& al., 2008). Por tal motivo, nuestras prácticas de extensión se implementan en la ciudad de La Plata y alrededores, siendo sus destinatarios inmediatos productores, gestores o docentes, por el efecto multiplicador de la experiencia que revierte sobre todos aquellos usuarios de estas plantas o productos elaborados.

\section{Juguemos con plantas}

La experiencia que aquí se describe consiste en el diseño e implementación de juegos que involucren plantas útiles y se realizó en coordinación con el personal de "La casa de Javi", una asociación civil de ayuda a niños y adolescentes con cáncer. Ésta realiza sus tareas en dos salas del área de pacientes oncológicos del Hospital de Niños de la Plata. Los niños permanecen hospitalizados durante períodos de diversa duración según la terapéutica, lo que hace que algunos de ellos estén escolarizados en la misma institución. Por este motivo se diseñaron propuestas lúdicas pero también educativas, a fin de ser implementadas en distintas instancias de acuerdo a la conveniencia.

Según Korstanje (2010) “en el juego humano interviene la capacidad de hacer uso de símbolos y signos para crear contextos, anticipar situaciones, planificar las acciones o interpretar la realidad". En consonancia con este planteo, a través de esta actividad se buscó por una parte transferir los saberes sobre plantas útiles a ámbitos y edades donde 
generalmente no se aplica este conocimiento, mientras que por otra parte se favoreció la reflexión y creatividad de los propios alumnos de Botánica Aplicada, directamente involucrados en la temática.

\section{Metodología}

El desarrollo de la experiencia constó de tres instancias. En una primera instancia se realizó un taller con los alumnos de la materia Botánica Aplicada, donde se trabajaron los conceptos mínimos a tener en cuenta en la elaboración de los juegos. A partir de allí, cada alumno diseñó dos juegos, de los cuales eligió uno que posteriormente fue confeccionado por completo. La consigna fue generar actividades recreativas y didáctico-lúdicas dirigidas a niños y que involucraran plantas de importancia cotidiana o las partes útiles de las mismas. Los criterios a tener en cuenta para la elaboración de cada juego fueron: el contexto de utilización, la factibilidad de realizarse, y los objetivos de cada uno. Para definir el contexto de utilización se consideró en primer lugar la edad estimada de los participantes. Se definieron 3 franjas etarias de trabajo según sus capacidades en lectoescritura e interpretación y análisis de textos: de 2 a 6 años, de 7 a 10 y de 11 a 14 años. En segundo lugar se tuvo en cuenta la movilidad implicada en las actividades recreativas, la cual debía explicitarse en las reglas. Por ejemplo, juegos que se podían hacer estando el niño sentado, acostado o siendo éste ambulante. Con respecto a la factibilidad, se tuvo en cuenta que los alumnos pudieran atender aspectos tales como estacionalidad de ciertas especies y disponibilidad de órganos vegetales, a fin de garantizar la realización de los juegos a lo largo del año. Además, atendiendo al hecho de que quienes manipularan estos juegos junto con los destinatarios finales serían el personal de la fundación y/o los docentes, se propuso elaborar una cartilla con las reglas de cada juego claramente escritas, con el propósito de poder ser llevados a cabo por cualquier persona que tuviera alcance a ellos.

En una segunda instancia, los alumnos presentaron por escrito la explicación de los juegos y confeccionaron la cartilla propuesta, para lo cual emplearon además recursos gráficos como diagramas, fotos o dibujos. Mediante ellos describieron las plantas involucradas en cada juego, que fueron mencionadas con nombre local y científico, caracterizaron sus órganos útiles y, en los casos pertinentes, dieron a conocer sus especies sustitutas.

En una tercera y última instancia, se realizó un taller con el personal de "La casa de Javi".

\section{Resultados}

\section{Fase de elaboración de los juegos}

A continuación, de los 23 juegos diseñados por los alumnos, se describen los 13 que fueron confeccionados efectivamente por ellos $\mathrm{y}$, en cada caso, se menciona su vinculación con los aspectos etnobotánicos y de botánica económica abordados durante el curso.

Juego $N^{o} 1:$ ¿Nos comemoslos colores? (Fig. 1A). Objetivo: que el niño pueda relacionar, a través del aprendizaje lúdico, los colores con los alimentos de origen vegetal que consume diariamente. Considerando que la forma de aprendizaje desde un primer momento es la curiosidad, se utiliza este motor para lograr que el niño vaya descubriendo la relación entre los colores y los alimentos que consume diariamente. La importancia de la actividad lúdica se ve reflejada en que no sólo interesa que el niño comprenda su entorno, sino que también pueda entretenerse y divertirse con la actividad, incentivándolo para futuros aprendizajes. Edad: 2-3 años. Tipo de juego: anillado de fichas con ventanas deslizantes organizadas por color. Elementos necesarios: fichas con ventanas deslizantes mediante las cuales se pueden cubrir y descubrir imágenes de frutas y verduras sus nombres y colores correspondientes. Dinámica del juego: se puede jugar sentado, requiriendo movilidad mínima. Se necesita un acompañante adulto para que estimule a los niños a descubrir cada planta. No posee un tiempo estipulado de duración y se puede jugar con uno o varios niños al mismo tiempo. Reglas del juego: El 


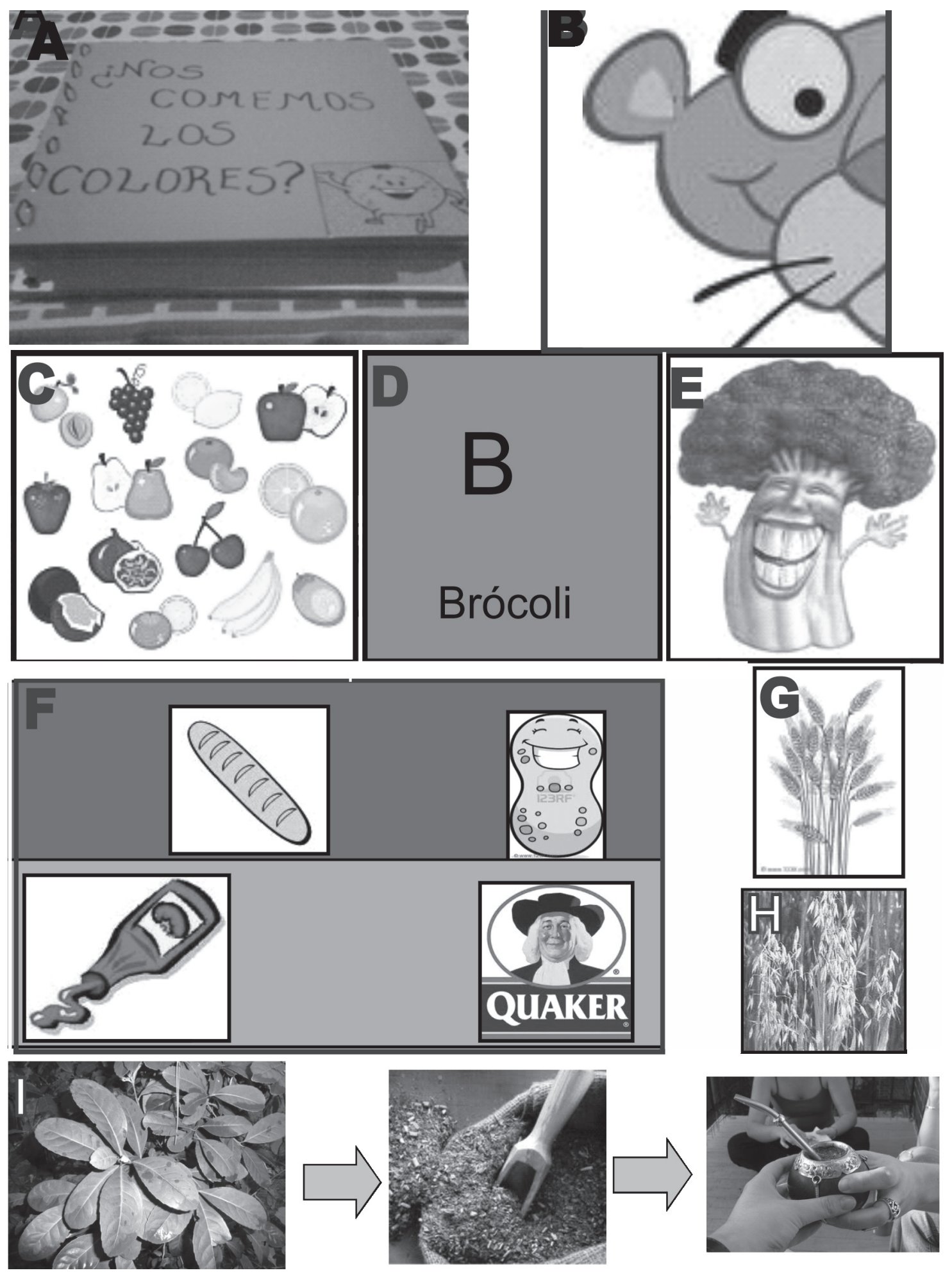

Fig. 1. Ejemplos de los juegos mencionados. A. Juego No 1 ¿Nos comemos los colores? B-E. Juego No 2 Memorizando. F-H. Juego $n^{\circ} 8$ ¿De dónde provienen? I. juego No 12 Cómo se hace? Conociendo las plantas que consumimos. 
adulto deberá orientar al niño para que éste pueda relacionar los colores con las frutas y verduras correspondientes, para esto se deslizan las ventanitas hacia un lado y hacia el otro descubriendo el nombre, color y la imagen de la misma. Relación del juego con la Etnobotánica y Botánica Aplicada: el mundo de las plantas, para la edad en la que se hallan los niños a los que está orientado este juego, es prácticamente desconocido, por eso llegar a ellos es bastante difícil, pero a su vez un desafío para nosotros. En el juego sólo se utilizan frutas y verduras, algunas comunes para ellos, como ser la banana y manzana, ya que son de fácil obtención en el mercado $\mathrm{y}$ resultan un alimento rápido y simple; $\mathrm{y}$ otras no tan conocidas como la berenjena y la espinaca que requieren de elaboración previa y su presencia puede ser menos evidente en alimentos procesados.

Juego No2: Memorizando (Fig. 1B-E). Objetivo: El interés del juego reside en observar atentamente las fichas que se dan vuelta reteniendo en la memoria el lugar que ocupaban para poder levantarlas cuando se las necesite y poder relacionar el nombre con su forma y color. Edad: a partir de los 5 años. Tipo de juego: juego de memoria con fichas. Elementos necesarios: 3 fichas con signo de interrogación (?), 1 ficha con la figura de la Pantera Rosa (Fig. 1B), 2 fichas con numerosas verduras que corresponden a los comodines (Fig. 1C), 15 fichas con figuras de plantas útiles (Fig. 1D) y 15 con su correspondiente nombre vulgar (1E). Dinámica del juego: juego de movilidad reducida donde pueden participar 2 ó más jugadores. Se requiere de una superficie relativamente amplia (mesa o suelo) donde poder ubicar las fichas. Se recomienda la participación de un mayor para ayudar a los niños con el reglamento. Reglas del juego: Comienza el participante más pequeño. Los niños deben estar sentados en ronda y el sentido de la misma será hacia la derecha del primer participante. Las fichas deben distribuirse sobre la mesa boca abajo para luego mezclarlas deslizándolas sin que se den vuelta. Luego, cada participante a su turno, debe dar vuelta primero una ficha y luego otra, tratando de encontrar el par imagen de planta- nombre correspondiente. Si lo consigue lo recoge y continúa jugando. Si no coincide la figura con el nombre correspondiente debe dejar la ficha hacia abajo en el mismo lugar donde estaba originalmente, y continúa el siguiente participante. En caso de dar vuelta la ficha con la pantera rosa, el jugador pierde su turno, porque esta ficha no tiene par. Luego de haber sido dada vuelta, esta ficha debe retirarse de la mesa de juego. La ficha con varias frutas, representa un comodín, el cual permite seguir sacando fichas un turno más, retirando luego la ficha del comodín del juego. Si el jugador sacara una figura con el signo de interrogación (?) significa que debe mencionar un numero del 1 al 10 para deducir una adivinanza; en caso de no adivinarla pierde su turno y la ficha vuelve al juego, pero si logra descifrarla esta ficha se retira y el jugador continúa sacando fichas. El juego finaliza cuando se acaban las fichas. Gana quien tenga más pares de fichas. Se detallan a continuación algunas de las adivinanzas planteadas con sus respuestas: 1) Una vaina soy y sin espada ni sable voy ( $\mathrm{La}$ chaucha); 2) Con el pelo rojo, la cara amarilla y llena de granos, soy rico alimento si estoy cocinado. (El maíz); 3) Verde me crié, rubio me cortaron, rojo me molieron y blanco me amasaron (El trigo); 4) Un señor coloradito nunca toma café siempre toma té, ¿quién es? (El tomate); 5) Zorra le dicen, ya ves, aunque siempre del revés, se lo come el japonés y plato muy rico es, ¿qué es? (El arroz); 6) Tiene dientes y no come, tiene cabeza y no es hombre, ¿qué es? (El ajo). Relación del juego con la Etnobotánica y Botánica Aplicada: con este juego se pretende que los niños interactúen con fichas de diferentes elementos como frutas, hortalizas, cereales, entre otros, y que puedan, conocer sus nombres, formas y colores de forma divertida, ya que se trata de utilizar figuras animadas para captar más su atención.

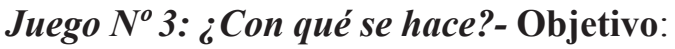
relacionar materia prima con productos obtenidos a partir de las mismas. Está dirigido a que los chicos tengan una noción de cuáles son los vegetales de los que provienen los alimentos que se compran procesados $\mathrm{y}$ envasados en el supermercado. Esto les 
permitirá además tener acceso a información complementaria como el lugar de donde provienen los vegetales empleados como materia prima, cómo son procesados y cuál era su aspecto original antes de ser transformados en alimentos comercializables. Edad: orientado a niños de 6 a 8 años. Tipo de juego: es un juego de asociación mediante imágenes. Elementos necesarios: para ejecutar el juego se requiere de las fichas de "materia prima" y "producto", las fichas informativas y las reglas correspondientes.

El juego costa de doce (12) pares de fichas "materia prima"- "producto" de uso diario (i.e. naranja-jugo de naranja, maíz- polenta, entre otros). Cada ficha "materia prima" aporta un dibujo que identifica al vegetal (materia prima) y que es acompañado por su nombre vulgar- salvo en aquellos casos en los que dar el nombre sea una pista muy directa para descubrir el producto, como es el caso de la yerba mate y del té. En estos casos cada ficha poseerá en su reverso una ayuda que permitirá al jugador identificar al vegetal. Todas las fichas "producto" poseen nombre. Dinámica del juego: Se recomienda dos a tres participantes como máximo y un auxiliar al cual recurrir si no se logra establecer una asociación, además de ser el que aporte la información contenida en las fichas informativas. Acerca del conocimiento del auxiliar del juego: es conveniente que el mismo posea un conocimiento básico de las materias primas vegetales, el procesamiento y las cualidades de cada producto elaborado. Para ello se adjuntan fichas informativas. Acerca del conocimiento de los jugadores: los requerimientos de los mismos son mínimos, o nulos, ya que pueden adquirirse durante el desarrollo del juego. La duración no excederá los 20 minutos. La movilidad requerida es mínima. Reglas del juego: la pila de fichas se tomará como un mazo y las fichas como cartas. 1-Se mezclan las cartas; 2- se reparten todas y se disponen boca abajo; 3 - al comenzar simultáneamente, los jugadores deberán dar vuelta una de las cartas para que todos puedan observarla; 4- el objetivo es asociar una materia prima con su producto, De no haber coincidencia materia prima-producto, se reitera el punto 3 tantas veces hasta lograrlo;
5- gana quien acumule mayor número de pares de fichas. El auxiliar deberá hacer un recuento de los pares de cada participante, y brindar alguna información útil de las fichas. Si más de un jugador descubre un par materia primaproducto al mismo tiempo, se desempata a través de una pregunta que realiza el auxiliar y quien conteste correctamente se llevará el par. Gana el fin que se lleva el mayor número de pares materia prima-producto. Relación del juego con la Etnobotánica y Botánica Aplicada: se busca que a través del juego, los participantes incorporen información relacionada con plantas útiles y su procesamiento, como por ejemplo,de qué plantas se obtienen muchos de los productos que utilizamos en la vida cotidiana para fines diversos (alimenticios, industriales, entre otros); qué órganos vegetales se utilizan; cómo y dónde se cultivan distintas plantas útiles y también dónde se realizó su domesticación (origen); el proceso industrial o artesanal que se aplica para obtener cada producto; la importancia de ciertos vegetales en la dieta humana.

Juego $N^{o}$ 4: Explora el uso de tu imagen. Objetivo: a través de este juego se busca que los chicos conozcan la amplia diversidad de usos que tienen determinadas materias primas vegetales y cómo dichos usos se corresponden a distintas necesidades humanas. Edad: 7-10 años (se puede acrecentar la edad según la dificultad del juego). Tipo de juego: juego de mesa con fichas. Elementos necesarios: fichas con imágenes de vegetales. Dinámica del juego: la movilidad del juego es mínima. La cantidad de participantes es de 3 personas. Se necesita la presencia de un adulto en lo que respecta a comunicarles a los chicos de forma detallada cada uno de los usos posibles de las distintas materias primas. Reglas del juego: Este juego consiste en una serie de cartas, las cuales se dividen en dos tipos. Un tipo se encuentra contenido en la bolsa 1, en ellas se encuentran tres opciones posibles de uso de para cada materia prima vegetal. El segundo tipo de cartas se encuentra en la bolsa 2, estas cartas tienen, en la parte de adelante, el nombre de una materia prima vegetal y por detrás, el uso que se le da a dicha materia prima, tapada 
con una solapa de papel para asegurarse que el jugador no la vea. Las cartas pertenecientes a la bolsa 1 se reparten de a 4 unidades entre 3 jugadores, pasando por distintos niveles de dificultad: simples y complejas (complejo en el sentido de hacer difícil el descubrimiento del uso/s correcto de la materia prima). Dentro de las cartas simples se encuentran el algodón (Gossypium hirsutum), la avena (Avena sativa), el té (Camellia sinensis), el arroz (Oryza sativa)), la canela (Cinnamomum verum) y la yerba mate (Ilex paraguariensis), mientras que dentro de las cartas complejas se encuentran el yute (Corchorus spp.), el olivo (Olea europea), el girasol (Helianthus annuus), el lino (Linum ussitatissimum), la mandioca (Manihot esculenta) y el algarrobo (Prosopis alba). Se empieza jugando con 2 cartas simples, luego de descubrir la opción correcta perteneciente a estas dos cartas simples se le agrega 1 carta compleja y luego se le agrega otra carta compleja. Una vez repartidas las cartas de la bolsa 1 , se seleccionará quien empieza el juego. El participante 1 tendrá que adivinar cuál es la opción correcta de las tres posibles opciones presentadas en su carta correspondiente sacada de la bolsa 1, una vez que éste comunicó cual es para él la opción correcta, el participante 2 que es el que le sigue, sacará de la bolsa 2 la carta que deberá tener el mismo nombre de la materia prima que la otra carta de la bolsa 1 que le tocó al participante para adivinar y le comunicará recién ahí cual era la opción correcta. A partir de aquí se pasará a la fase de ver cuántos puntos ha conseguido cada uno de los participantes, para esto se deberá saber que en el primer nivel de dificultad será 1 punto por cada opción correcta perteneciente a la carta simple, en el segundo nivel de complejidad se seguirá respetando un punto por cada opción correcta de la carta simple más 2 puntos por la opción correcta de la carta compleja y en el tercer nivel de complejidad será 1 punto por cada opción correcta de las cartas simples, 2 puntos por la opción correcta de la primer carta compleja y 3 puntos por la carta compleja que se agrega en esta última instancia del juego. Todos estos puntos de sumarán y el que tenga más puntos será el ganador del juego. Relación del juego con la Etnobotánica y
Botánica Aplicada: este juego se relaciona con el rol que ciertas plantas cumplen como materia prima de bienes usados por los seres humanos, vinculando caracteres propios de las plantas con necesidades humanas y el proceso de manufactura de ciertos bienes a través de la industrialización de las plantas.

Juego $N^{o} 5$ : Adivina la hoja. Objetivos: este juego busca despertar la curiosidad y ejercitar la observación de sus participantes. En el mismo se intenta brindar algún conocimiento básico sobre la forma de la hoja de árboles urbanos, pudiendo esto despertar en ellos una suerte de interés por las plantas que nos rodean en la ciudad y de esta manera poder lograr un cambio en el trato y cuidado del arbolado urbano. Edad: a partir de los 7 años. Tipo de juego: este juego de mesa botánico está inspirado en el ya conocido "Adivina Quien" C. Elementos necesarios: 8 pares de tarjetas con hojas de diferentes árboles; glosario; 3 hojas con figuras de formas vegetales básicas; dos tableros de cartón. Dinámica del juego: este juego requiere de una movilidad reducida. El número de participantes es de dos personas. Reglas del juego: En este juego se trata de que, por medio de la observación de las figuras contenidas en tarjetas ubicadas en un tablero, cada jugador genere preguntas que le permitan identificar la figura del otro participante. Para comenzar a jugar ambos jugadores deben sentarse enfrentados entre sí y deben ubicar delante de ellos un tablero. Una vez hecho esto, los participantes deben repartirse las tarjetas de modo tal que cada uno cuente con una figura de cada par (ej.: una tarjeta del tilo, una tarjeta del olmo, etc.). Una vez repartidas todas las tarjetas, las mismas deben ubicarse en el tablero, teniendo cada participante 8 tarjetas con figuras diferentes. Luego, cada participante debe elegir una de sus tarjetas y mantenerla en secreto, apartada del resto de las figuras del tablero. Luego juegan "piedra papel o tijera" para ver quién empieza. El ganador comienza a hacerle preguntas a su compañero a fin de adivinar cuál es la figura que está en la tarjeta que eligió su compañero en secreto. Las preguntas deben ser de tal tipo que las respuestas posibles sean "Sí" o "No". Luego de esto pueden suceder dos cosas: a. si 
el interrogado responde afirmando la pregunta hecha por el interrogador (respondiendo "Sís"), éste puede seguir preguntando hasta descubrir la identidad de la figura secreta del contrincante, b. si el interrogado responde negativamente a la pregunta (respondiendo "No"), otorga el turno de preguntar del contrincante haciendo lo propio de la misma manera que su par contrario. Si uno de los dos jugadores advierte que la respuesta es falsa el contrincante quedara automáticamente descalificado. Una vez que uno de los jugadores arriesga el nombre de un árbol y acierta, el que respondía las preguntas debe entregarle la ficha donde figura el árbol en cuestión, el jugador que acertó toma la ficha del mismo árbol de su tablero y queda para su pozo, el cual va acumulando a uno de los lados del tablero. Cuando ya no hay más tarjetas en los tableros se contará cuantos pares de fichas tiene cada jugador y el que tenga más tarjetas gana. Debido a la cantidad de fichas que tiene este juego se puede empatar, y optar por la revancha!!. El glosario y las figuras estarán en la mesa durante todo el desarrollo del juego para ser consultadas para la formulación de preguntas y para el mejor entendimiento del juego. Relación del juego con la Etnobotánica y Botánica Aplicada: en los últimos años se ha vuelto usual que en las grandes ciudades, las plazas y los parques sean un lugar de relajación y entretenimiento para la gente que en ellas vive. Es así que los seres humanos -más precisamente en las últimas dos décadas- han encontrado en estos lugares el mejor espacio para practicar todo tipo de actividades recreativas, culturales y festivas, aunque generalmente se desconozca debajo de qué árboles se están llevando a cabo las mismas. Por lo tanto, es esta relación entre el Hombre y el arbolado urbano lo que se pretende reforzar mediante un conocimiento básico de la forma de las hojas de árboles de la ciudad y sus alrededores para reconocerlos in situ, esperando que ello redunde en su valoración y conservación.

Juego $N^{o}$ 6: El juego de la oca botánico. Objetivos: A través de la recreación, se espera que se asocien plantas con los usos que les dan los seres humanos. Edad: de 8 años en adelante. Tipo de juego: este juego de mesa está inspirado en el ya conocido juego de la oca. Elementos necesarios: tablero, dado y fichas con forma de plantas. Dinámica del juego: es un juego de mesa con movilidad moderada ya que existen prendas en las que los participantes tienen que realizar actividades con su cuerpo. Reglas del juego: Una vez dispuesto sobre la mesa el tablero, cada participante elige una ficha de color. Aquí comienza el recorrido: los jugadores deberán proceder a tirar el dado y el que obtenga el número mayor comenzará el juego, siguiendo la ronda hacia su derecha. Cada jugador tira el dado en su turno y mueve la ficha el número de casillas que indica el dado. Si el jugador aterriza en una casilla con la oca pasa a la oca inmediatamente siguiente y vuelve a tirar los dados. Si aterriza en una de las casillas especiales, el jugador puede recibir la instrucción de perder uno o más turnos, avanzar o retroceder un número determinado de espacios, contestar preguntas, o seguir las instrucciones que se detallan a continuación. En caso de no contestar correctamente cualquiera de las preguntas o no poder seguir las consignas de las prendas, el participante perderá un turno. El ganador será aquel que primero llega al casillero final. A continuación se detallan algunas de las preguntas e instrucciones para los casilleros especiales: Casillero 3- Hacer malabares con 2 pelotitas, si se cae una al piso pierde un turno; Casillero 5- Oca. Avance hasta la próxima oca y tire los dados. Casillero 6- ¿Qué parte de la plantas de zanahoria se utiliza como alimento? (La raíz), Casillero 9- Pierde un turno. Casillero 10- Responder: ¿Con granos de qué cereal se hacen los pochoclos? (Con granos de maíz). Casillero 12- Retrocede 2 casilleros. Casillero 14- Responder: ¿Con los frutos de qué planta se hace el vino? (Con los frutos de la vid : uvas). Casillero 15- Avanza 2 casilleros. Casillero 54- Pierde un turno. Casillero 57Retroceda 2 casilleros. Casillero 60- Llegada. Relación del juego con la Etnobotánica y Botánica Aplicada: este juego se vincula con la etnobotánica puesto que implica relacionar diferentes plantas con los usos que el Hombre les da, además de tener que poner en relación distintas partes orgánicas de una misma planta con diferentes usos específicos. La idea es que 
los participantes puedan relacionar comidas, vestimenta, y demás aspectos de la vida cotidiana, con las plantas de donde se extraen y con la parte de la misma que se utiliza para tales fines. Además se busca que los niños conozcan el lugar de origen de algunas plantas también muy familiares como la yerba mate o el arroz, cuyo origen pueden desconocer, pero se espera que puedan deducir a partir del conocimiento previo (por ejemplo es típico en varias películas ver que el arroz se come en China, por lo que pueden deducir su origen), o deducir a partir de opciones que se dan para facilitar las respuestas.

Juego $N^{o}$ 7: ;A poner todo en orden!. Objetivo: poner en orden fichas que representan las secuencias relacionadas con la agricultura con el fin de que, mediante el ejercicio lúdico y fomentando capacidades relacionales y secuenciales, los niños puedan reconocer y aprender los procesos que esta práctica implica. Edad: orientado a niños a partir de los 8 años. Tipo de juego: juego de mesa con fichas para ordenar en secuencias, de diferentes dificultades. Elementos necesarios: sobres con fichas que representan diferentes etapas agrícolas de cada planta. Dinámica del juego: juego de mesa con movilidad mínima. Reglas del juego: Cada sobre de este juego contiene fichas que representan una secuencia agrícola determinada, cuya complejidad se basa en el número de fichas que lo componen. Cada jugador deberá elegir un sobre y poner las fichas que hay dentro de él en el orden que considere correcto. En algunos casos, la descripción en la ficha sirve de ayuda para ordenarlas con el criterio de "ordenar de principio a fin". Relación del juego con la Etnobotánica y Botánica Aplicada: el juego lleva a incorporar la idea de cómo se realizan actividades relacionadas con el cultivo de plantas en general y con la huerta en particular. En este juego se indican las etapas involucradas en el quehacer agrícola y lo que el Hombre obtiene a partir de dicha actividad y sus prácticas involucradas.

Juego $N^{o}$ 8: ¿De dónde provienen?. Objetivo general: Se busca que el niño comprenda la importancia de los vegetales en la vida del hombre, conozca de dónde provienen los alimentos que consumimos y qué tan cerca están de nosotros, por ello se propone relacionar y asociar, a través del aprendizaje lúdico, diferentes productos alimenticios de origen vegetal con su materia prima. Edad: a partir de los 8 años.

Tipo de juego: juego de mesa, de asociación y educativo. Elementos necesarios: un tablero por jugador con imágenes de vegetales procesados (Fig. 1F), fichas con imágenes de vegetales sin procesar (Fig. $1 \mathrm{G}, \mathrm{H}$ ), ruleta con imágenes de vegetales

Dinámica del juego: juego de mesa con movilidad mínima. Reglas del juego: Se reparte un tablero ilustrado a cada jugador. Las doce fichas con las imágenes de los vegetales se colocan boca arriba sobre la mesa. Cualquiera puede comenzar el juego. El jugador 1 hace girar la ruleta en donde están las imágenes de los vegetales (materia prima) y observa sobre qué vegetal se detiene la flecha. Luego deberá buscar la imagen que le tocó en la ruleta entre las fichas que están boca arriba sobre la mesa. Una vez que encuentra la ficha que ilustra el vegetal que le tocó en la ruleta, la toma y deberá asociar la misma a uno de los productos que están en su tablero, dicha asociación debe hacerse considerando qué producto se obtiene del vegetal que le tocó. Una vez que lo logra adivinar, colocará la ficha sobre la ilustración correspondiente del tablero. Si no logra relacionar la ficha con el producto que se corresponde, vuelve a colocarla boca arriba sobre la mesa y pasará el turno al jugador siguiente. Ganará el juego quien logre completar primero su cartón con las asociaciones correctas. Para constatar si las asociaciones hechas son correctas o no, se puede mirar (recién al finalizar el juego) la hoja de respuestas adjunta. Relación del juego con la Etnobotánica y Botánica Aplicada: la utilización de la Etnobotánica como recurso didáctico, permite introducir al juego el conocimiento de las plantas útiles vinculadas a las prácticas culturales cotidianas, plantea una forma de acercamiento para conocer en qué medida dependemos de ellas y cuán presentes están en nuestra vida cotidiana.

Juego $N^{o}$ 9: Texturas, formas y aromas. 
Objetivo: la propuesta de este juego se fundamenta en la estimulación de los sentidos del tacto, el oído y el olfato para conocer algunos de los tantos productos vegetales que forman parte de nuestro entorno y no siempre advertimos. Edad: a partir de 8 años. Tipo de juego: juego de interacción y conocimiento a través de los sentidos. Elementos necesarios: tarjetas con nombres de las plantas (vulgares y científicos) y preguntas referidas a las mismas. Estas tarjetas están contenidas en una bolsa e incluyen las siguientes plantas: canela (Cinnamomum verum); nuez moscada (Myristica fragrans); orégano (Origanum spp.); arroz (Oryza sativa); maíz (Zea mays); algodón (Gossypium hirsutum); girasol (Helianthus annuus); garbanzo (Cicer arietinum); lenteja (Lens culinaris); cúrcuma (Curcuma longa); azafrán (Crocus sativus); tomillo (Thymus vulgaris); laurel (Laurus nobilis); café (Coffea arabica); té (Camellia sinensis); cacao (Theobroma cacao); yerba mate (Ilex paraguariensis); yute (Corchorus olitorius y Corchorus capsulares); lino (Linum usitatissimum); maní (Arachis hypogaea); sisal (Agave sisalana); coco (Cocos nucifera); ajo (Allium sativum); manzanilla (Matricaria chamomilla); trigo(Triticumaestivum); lavanda (Lavandula officinalis); cilantro (Coriandrum sativum); perejil (Petroselinum crispum); boldo (Peumus boldus). Frascos que contienen partes útiles de las plantas mencionadas. Venda para los ojos. Dinámica del juego: juego con movilidad mínima. Reglas del juego: el juego consiste en reconocer distintas plantas mediante el tacto o el olfato. Antes de jugar se puede realizar una ronda de reconocimiento donde los participantes tengan acceso al contenido de los frascos y puedan ver, oler y tocar su contenido. También es recomendable, luego de esta ronda, elegir las plantas que crean que serán más fáciles de reconocer para comenzar a jugar y luego ir introduciendo las menos conocidas. Cada jugador, a su turno, se venda los ojos y saca una tarjeta de la bolsa, la cual entrega a otro participante. Este último participante lee la tarjeta ( $\sin$ decir nada en voz alta) y toma de la caja el frasco con la muestra correspondiente a la tarjeta. Le acerca el frasco al participante vendado para que lo pueda oler, o le pasa parte de la muestra para que la toque. Si el participante vendado reconoce de qué muestra se trata suma 5 puntos. Por cada pregunta de la tarjeta que el participante responda bien suma 1 punto más. Gana el jugador que obtenga más puntos luego de una ronda. Relación del juego con la Etnobotánica y Botánica Aplicada: se procura reforzar la relación Hombre-planta incrementando el conocimiento que los niños tienen de algunas "plantas útiles" al momento que se divierten jugando. Los caracteres organolépticos son usualmente empleados en Botánica Aplicada para el reconocimiento de muestras de vegetales útiles cuyo estado de fragmentación dificulta su reconocimiento a ojo desnudo. A su vez, estos caracteres son empleados usualmente por la gente en distintas sociedades y/o comunidades a lo largo del planeta para clasificar a las plantas útiles, sobre todo aquellas con propiedades biodinámicas.

Juego $N^{o}$ 10: El pictionary vegetal. Objetivo: este juego pretende, desde la diversión y la recreación, generar conocimientos básicos sobre distintos tipos de plantas. El juego propone 5 categorías en las que se pueden agrupar los vegetales y requiere que los participantes, a través de dibujos, logren que sus compañeros identifiquen la planta elegida. También se cuenta con pistas -breves adivinanzas escritas en cada tarjeta- que pretenden, desde lo lúdico y lo educativo, dejar una pequeña enseñanza o conocimiento sobre cada planta en particular. Edad: 11 a 14 años. Tipo de juego: juego de asociación y coordinación, mediado a través del dibujo. Elementos necesarios: Reloj, papel, lápiz y 52 tarjetas a color divididas en 5 categorías distintivas, cada una de las cuales se indica con un color específico. TARJETAS ROJAS: plantas que sirven como alimento (alimenticias). TARJETAS VERDES: plantas que sirven como condimentos (condimenticias). TARJETAS AZULES: plantas que sirven para hacer telas (textiles). TARJETAS NARANJAS: plantas que sirven para mejorar la salud (medicinales). TARJETAS VIOLETAS: plantas cuyos frutos son consumidos (frutas). En cada una de ellas está escrito el nombre de un vegetal o una parte de él, una pista y el puntaje de la 
respectiva tarjeta. Dinámica del juego: juego de mesa con movilidad mínima. Reglas del juego: Se toman las 52 tarjetas y se procede a mezclarlas, se las coloca boca abajo en una pila y se forman equipos de igual cantidad de integrantes. Un miembro de cada equipo toma una tarjeta de la pila sin que nadie vea qué hay dibujado en la misma, éstos serán los encargados de dibujar cualquier cosa que les permita a sus compañeros de equipo identificar el vegetal asignado. Cada equipo tiene 1 minuto para dibujar y adivinar, de hacerlo en ese tiempo obtienen los puntos asignados en la tarjeta, de lo contrario el encargado de ilustrar procederá a leer una pista que ayudará a su equipo a adivinar, si lo hacen ganan la mitad de los puntos asignados en la tarjeta, de no adivinar en ninguna de las dos instancias, el equipo no suma puntos. El procedimiento se repite alternando los jugadores que dibujan en cada equipo. Las tarjetas utilizadas no pueden volver a ser puestas en la pila. El juego finaliza cuando se acaban las tarjetas (o en su defecto cuando el número de tarjetas remanente en la pila sea menor al número de equipos) y el equipo ganador es el que haya obtenido más puntos. Relación del juego con la Etnobotánica y Botánica Aplicada: el juego se relaciona directamente con la etnobotánica a través de las tarjetas y sus colores que buscan agrupar los vegetales asignados para el juego en categorías utilitarias según la finalidad cotidiana que se les atribuye a las distintas plantas. Al asociar las tarjetas a colores y a su vez, cada color a una categoría, los jugadores podrán poco a poco recordar las plantas que se utilizan para funciones específicas apelando a rememorar el color de tarjeta que se extrajo, lo que servirá de ayuda para adivinar la misma.

Juego N ${ }^{o} 11$ : Dígalo con lápiz. Objetivo: el objetivo del juego es poder demostrar y/o incorporar, mediante sus habilidades en dibujo e imaginación, conocimiento sobre plantas comestibles y condimenticias. Edad: 10 a 14 años. Tipo de juego: juego de mesa con tarjetas que estimula la creatividad e imaginación. Elementos necesarios: reloj de arena, papel, lápiz y fichas con imágenes de plantas y datos como por ejemplo lugar de origen, parte utilizada, valor nutricional (V.E.) y nombre científico. El color amarillo indica plantas más conocidas (y por ende "fáciles") y el rojo plantas menos conocidas (y por ende "difíciles"). Dinámica del juego: juego de mesa con movilidad mínima. Reglas del juego: El integrante del equipo de turno saca una tarjeta sin que nadie más vea su contenido, deberá informar en voz alta solamente el coloreado que tiene el nombre de la planta. Dependiendo del color va a ser el puntaje asignado al ser adivinada. El reloj de arena comienza a contar, éste deberá darse vuelta una vez, o sea el turno es de dos vueltas del reloj. Rápidamente el jugador debe dibujar lo que le tocó en la tarjeta, mientras que el resto de sus compañeros intentan adivinar de qué planta se trata. El jugador debe pasarle la tarjeta al (los) equipo(s) contrario(s) para que sus miembros vean el contenido de la misma y puedan actuar como jurado. Si el equipo en juego adivina, se le otorga una cantidad de 5 puntos en el caso de tratarse de tarjetas coloreadas rojas y 3 puntos a las coloreadas amarillo. Luego, si el equipo que está jugando desea agregar más información sobre la planta, como por ejemplo lugar de origen, parte utilizada, valor nutricional (V.E.), nombre científico, etc., puede arriesgarse a decir esta información. El jugador que dibujó, junto al (los) equipo(s) contrario(s) dictaminará si la respuesta es correcta y, de serlo, cada aporte sumará 1 punto extra. Si el equipo acierta antes de que acabe el tiempo, vuelve a sacar otra tarjeta y así hasta que el reloj de arena acabe. Relación del juego con la Etnobotánica y Botánica Aplicada: en los conglomerados urbanos, a diferencia de las sociedades tradicionales, donde el vínculo entre la producción y el consumo es directo (de la huerta a la mesa), muchas personas conocen sólo de modo ocasional los componentes y el valor alimentario de las plantas que consumen y, rara vez, su origen botánico y geográfico. Este juego, además de entretener, aporta datos sobre esta última información a niños que habitan ámbitos urbanos.

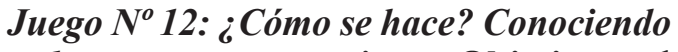
las plantas que consumimos. Objetivos: el objetivo principal del juego es dar a conocer las plantas y el modo de producción de 
aquellos productos que utilizamos diariamente como la harina de trigo o de maíz, aceite de soja, oliva o girasol, las prendas que utilizamos de algodón, la yerba para el mate y las uvas para el vino, entre muchas otras. Por lo tanto el juego apunta a seguir los procesos de transformación que atraviesa una planta útil, aportando información desde que la misma se domesticó o empezó a utilizar, hasta las provincias donde hoy en día se cultivan en Argentina, detallando el recorrido desde que se siembra hasta que llega como producto al supermercado. Edad: de 11 a 14 años. El juego está orientado a este grupo etario ya que se necesita de la lectura y comprensión de los textos dados en las tarjetas, así como también de ciertos conocimientos previos (aunque no sean estrictamente necesarios, es bueno que cuando lean por ejemplo, de dónde es originaria una planta útil, o dónde se cultiva hoy en Argentina, sepan ubicarse geográficamente de forma aproximada). Tipo de juego: juego de mesa. Elementos necesarios: El juego consta de: 1 dado que posee colores en lugar de números, cada color tiene su significado (rojo: indica que debe sacar una tarjeta "¿Sabías qué?", y avanza un casillero; azul: indica que debe avanzar un casillero; verde: indica que debe avanzar 2 casilleros; amarillo: indica que debe avanzar 3 casilleros; naranja: indica que debe avanzar un casillero y que cambia de sentido la ronda; rosa: indica que debe sacar una tarjeta "¿Sabías qué?" pero no avanza ningún casillero); 1 tablero con un recorrido inicial igual para todos los jugadores (a modo didáctico y para simplificar el juego se considerará una etapa inicial igual para todas las plantas, pero hay que tener en cuenta que no todas las plantas útiles incluidas en el juego son anuales) y 9 recorridos, uno por cada planta útil, desde la cosecha hasta la venta del producto manufacturado; 9 fichas: cada una representa una planta útil: trigo (Triticum aestivum); girasol (Heliantus annus); algodón (Gossypium hirsutum); yerba mate (Ilex paraguariensis) (Fig. 1I); maíz (Zea mays); vid (Vitis vinifera); soja (Glycine max); caña de azúcar (Saccharum officinarum); oliva (Olea europaea); 9 "Tarjetas de Inicio"; 42 tarjetas “¿Sabías qué?”. Dinámica del juego: juego de mesa con movilidad mínima. Reglas del juego: 1 . Un participante toma las 9 fichas que representan plantas útiles, las mezcla y reparte al azar las mismas entre los jugadores. Cada participante debe tomar la "Tarjeta de Inicio" que se corresponda con la planta útil que le tocó, pero no debe leerla hasta que comience el juego; 2. Para comenzar a jugar todos deben tirar el dado, quien obtenga el color verde es el que comenzará a jugar. En el caso de que a 2 o más participantes hayan sacado el mismo color, deberán tirar nuevamente el dado tantas veces hasta que 1 solo jugador obtenga el color. El siguiente en jugar será el que esté a la derecha del $1^{\circ}$ jugador y así sucesivamente; 3 . Cada jugador antes de tirar el dado por primera vez en su turno correspondiente, deberá leer la "Tarjeta de Inicio" en voz alta, que le dará a conocer características particulares de la planta útil que le tocó; 4. Y comienza el juego! Las fichas deben ubicarse en el punto de inicio, la primera parte del recorrido es la misma para todos los jugadores. El primer jugador luego de leer su tarjeta, tira el dado y según el color que saque será lo que deberá hacer... (ver descripción del dado); 5. Casilleros "malos": en ciertos momentos del recorrido hay algunos casilleros que indican que pasó algo malo (por ejemplo, las plagas se comen los frutos), por lo cual el jugador deberá retroceder y ubicar su ficha en el casillero indicado (por ejemplo, en el casillero de las plagas indica que debe volver al inicio); 6. Casillero "Pare": una vez que llegan a este casillero deben parar, no importa si deberían recorrer más casilleros debido al color de dado obtenido. Una vez que paran aquí automáticamente la ficha del jugador deberá ser ubicada en el inicio de su recorrido particular (es decir, donde está escrito el nombre de la planta útil) correspondiente a su planta y deberá esperar a su siguiente turno a tirar el dado para continuar su recorrido; 7. Fin del juego! El ganador será aquel que primero llegue al final del recorrido, la venta al público. Relación del juego con la Etnobotánica y Botánica Aplicada: Este juego está estrechamente relacionado con la etnobotánica ya que muestra a lo largo de todo su recorrido, y en cada uno de sus casilleros o información que brinda a través de fichas, la relación del Hombre con las plantas con énfasis en las acciones que 
las sociedades humanas realizaron para que las plantas aumenten su rendimiento. Por ejemplo, inicios de la domesticación, primeros usos tradicionales, y el recorrido en la cadena industrial que presentan hoy en día, partiendo de la siembra, pasando por la cosecha y detallando su manufacturación hasta obtener los productos que consumimos a diario.

Juego $N^{o}$ 13: La aventura del Teyú Cuaré. Objetivos: Este juego apunta a fomentar la lectura en voz alta, la imaginación, y la búsqueda de información por parte de los niños. Los juegos de mesa temáticos tienen un tema o ambientación asociado. Son aquellos cuyos elementos - fichas, dados, tablero, etc. - representan en alguna medida el comportamiento y características de seres u objetos reales o imaginarios. Los objetivos específicos de este juego, en particular, intentan plasmar en sentido figurativo e imaginativo la utilidad de los conocimientos asociados a las plantas de la selva misionera. Sus recorridos se basan en la búsqueda de recursos vegetales, sean éstos primarios, como la obtención de alimento o de fibras para diferentes objetivos, o también recursos secundarios, como por ejemplo la sombra o el valor paisajístico. De forma amena se introducen nociones botánicas básicas, como cierto vocabulario y el uso de nombres científicos para denominar a las plantas. Este acercamiento científico se relaciona constantemente con el saber indígena o criollo local, a fin de dar a entender la riqueza que yace en el intercambio de conocimientos y formas de percibir la naturaleza. Específicamente se intenta: 1-mostrar que las fronteras geográficas y socio-cuturales con el vecino país de Paraguay son arbitrarias, ya que las costumbres y conocimientos son compartidos, trascendiendo las mismas; 2-estimular las ganas de leer y la capacidad de entendimiento de situaciones novedosas asociadas a las plantas y ambientes en el contexto de la Selva Misionera; y 3-expresar algunos procesos culturales asociados a la ciencia, el arte, la salud, así como la producción y comercialización en el marco de la sociedad donde el juego sucede. Edad: 11-14 años. Tipo de juego: juego de mesa con tablero y lectura de cartilla asociada. Elementos necesarios: 1 tablero; 1 Cuadernillo; 6 Fichas (flechas numeradas del 1-6 y de colores diferentes); 6 tarjetas rojas; 1 dado; 1 moneda (con caras inscriptas con las letras I "izquierda" y D "derecha"); 1 planta herborizada. Dinámica del juego: juego de movilidad mínima. Reglas del juego: el juego consiste en viajar desde un nodo inicial ( $\mathrm{La}$ aldea) a través de distintos caminos. En éstos se enfrentan diferentes situaciones asociadas con la selva misionera y sus habitantes. Antes de iniciar el juego uno de los participantes debe leer el resumen de las 2 primeras páginas que se encuentra en el cuadernillo asociado. Para iniciar el juego los jugadores deben tirar el dado, el cual determinará qué número de jugador es cada participante y desde qué camino debe salir en el tablero (el número de jugador y el número de camino de salida coinciden). A su vez es este número el que definirá el orden de la ronda. Ejemplo: si al tirar el dado sale el número 3, al jugador le corresponde la ficha número 3 . El mismo debe iniciar el juego por el camino $3 \mathrm{y}$ tercero será siempre su turno en la ronda. Una vez configurados los caminos de todos los participantes, el jugador número 1 debe viajar al primer nodo que se encuentra en su camino. En el nodo se indica el número de página donde debe abrir el cuadernillo. Allí debe leer en voz alta la descripción del nodo en que se encuentra, una vez hecho esto debe tirar el dado, el cual le dirá cuál de las 6 opciones que ofrece el nodo debe leer. La opción asignada (tarea y misión) deberá leerse en voz alta a todos sus compañeros, así como llevarse a cabo según lo que se indique en la opción. Ejemplo: viajando a donde se le indique, quedarse donde está y esperar su próximo turno para tirar el dado, o esperar allí y perder un turno en la próxima ronda. En caso de perder el turno el participante debe tomar una tarjeta roja, esto recordará al resto de los participantes que en la próxima ronda pierde el turno para evitar olvidos. Una vez cumplimentada la pérdida del turno debe devolver la tarjeta roja y seguir jugando. Cuando avanza el jugador en el tablero siempre lo debe hacer por donde lo indique la opción del nodo. Ejemplo: viajas a los Peñones del Teyú Cuaré vía Casa de Horacio Quiroga-Puerto del Paraná. Las 
fichas, que poseen forma de flecha, deben posicionarse sobre el "sendero" indicando así desde dónde vino el jugador y señalando el nodo donde se encuentra (la ficha no debe ser colocada sobre el). En algún momento del juego dentro de las opciones de los nodos se le puede pedir al jugador que tire la moneda, la cual contiene las inscripciones "I" y " $D$ ". Estas opciones definirán si viaja al nodo de la izquierda o al de la derecha. El juego finaliza cuando un jugador logra llegar a la aldea Mbyá-guaraní Argentina. La clave del juego es el azar, para ello está el dado y la moneda.

Relación del juego con la Etnobotánica y Botánica Aplicada: este juego temático tiene sus bases en el conocimiento etnobotánico. El conocimiento botánico tradicional suele asociarse a aquél generado por pueblos que establecen una relación directa con el medio natural que los circunda, resultado de varias generaciones en que dicha relación se ha gestado, reproducido y transformado. Es un conocimiento comunitario generado durante cientos de años, pero en constante evolución, implicando procedimientos de innovación progresiva y acumulativa. E1 conocimiento botánico tradicional, en tanto propiedad cultural e intelectual de un pueblo, forma parte de su patrimonio tanto intangible (conocimiento sobre el medio y cómo operar en relación al mismo), como tangible (plantas y ecosistemas modificados, productos obtenidos, etc.) y por ende está en relación directa con la identidad de dicho pueblo. Las herramientas lúdicas brindadas en el juego les servirán a los niños para leer las descripciones de las plantas empleadas, la noción de nombre local y científico, así como cuándo intervienen órganos útiles y cuál es la planta completa a la que pertenecen. Datos accesorios como el origen, cosmovisiones asociadas a las plantas y significado y asociaciones a los nombres comunes y científicos de las plantas son también abordados en este juego.

\section{Fase de transferencia de los juegos propuestos}

Al finalizar el diseño y confección de los juegos antes mencionados se realizó un taller con el personal de "La casa de Javi".
Durante el mismo, los alumnos explicaron los dos juegos elaborados por cada uno de ellos y realizaron la demostración empírica del juego que tuvieron que confeccionar, el que luego fue obsequiado a los talleristas. Se entregó también una cartilla explicativa con la totalidad (23) de los juegos diseñados, De esta manera, se capacitó al personal de la fundación para que puedan poner en práctica los mismos durante su trabajo semanal con los niños en el hospital.

\section{Conclusiones}

En consideración de los principios postulados por la Universidad Nacional de La Plata para la Extensión Universitaria (Secretaría de Extensión UNLP, 2008) las prácticas de extensión en Botánica Aplicada son destinadas a promover actividades: 1. que transfieren al entorno extrainstitucional los conocimientos y las experiencias producidos por la investigación mediante su aplicación o adaptación (en nuestro caso información sobre plantas útiles de uso cotidiano); 2. formativas de grado que mediante la capacitación, prevención, orientación, información y difusión o asesoramiento a la comunidad, permitan complementar con la práctica, la formación teórica curricular (los alumnos de Botánica Aplicada, a través de esta experiencia, aplican los conocimientos adquiridos en la resolución de problemas cotidianos); y 3. de acción social, como una modalidad de la extensión caracterizada por acciones que aporten un beneficio a las comunidades de la región, como forma de contribuir a la resolución de necesidades y problemas concretos (en esta experiencia se busca contribuir a la incorporación de saberes botánicos por parte de niños y jóvenes en situación crítica a través de una actividad lúdica).

En suma, desde la perspectiva de la etnobotánica aplicada, y a partir de la implementación de las Prácticas de Extensión en la cursada de Botánica Aplicada, se ha logrado involucrar a los alumnos de las licenciaturas en Biología y Antropología que cursan esta materia, en la problemática de la diversidad biocultural, y su aplicación en la resolución de problemas 
planteados por pobladores de nuestro medio referidos al uso y conservación de recursos vegetales, así como en la difusión de saberes escasamente tratados en entornos urbanos, como el medio con el que interactuamos.

\section{Bibliografía}

KORSTANJE, M. A. 2010. Lo lúdico, lo creativo y lo formalizado en la investigación del pasado: expandiendo saberes en arqueobotánica. En M.L. Pochettino, A.H.Ladio y P.M.Arenas (eds.), Tradiciones y transformaciones en Etnobotánica, pp. 76-82. Ed. Cyted, S.S. de Jujuy.

MARTÍNEZ CROVETTO, R. N. 1968a. Viejos juegos de los indios mocovíes. Etnobiológica 2: 1-31.

—. 1968b. Algunos juegos de los indios vilelas. Etnobiológica 5: 1-19.

—. 1968c. Juegos y deportes de los indios guaraníes de Misiones (República Argentina). Etnobiológica 6: 1-30.

. 1968d. Estudios sobre juegos Araucano-Pampas. Etnobiológica 8: 1-30.

1968e. Algunos juegos infantiles criollos e indígenas del norte argentino. Etnobiológica 9: $1-14$.

__. 1969. Juegos araucanos de la Patagonia. Etnobiológica 13: 1-24.

—. 1970. Juegos de hilo de los aborígenes del norte de la Patagonia. Etnobiológica 14: 1-85.

POCHETTINO, M. L., P. M. ARENAS, D. SÁNCHEZ \& R. CORREA. 2008. Conocimiento botánico tradicional, circulación comercial y consumo de plantas medicinales en un área urbana de Argentina. Bol. Latinoam. Caribe Plant. Med. Aromaticas 7 (3): 141-148.

SECRETARÍA DE EXTENSIÓN UNLP. 2008. http:// www.unlp.edu.ar/articulo/2008/4/10/extension_ apertura_institucional. (accesado 14/06/2011).

Original recibido el 15 de julio de 2011; aceptado el 25 de noviembre de 2011. 
